\title{
Dietary protein and preference for sweets in the female rat
}

\author{
ELLEN F. ROSEN \\ College of William and Mary, Williamsburg, Virginia 23185 \\ and \\ LINDA C. PETTY \\ Hampton Institute, Hampton, Virginia 23668
}

\begin{abstract}
Adult female albino rats were fed either a normal protein $\operatorname{diet}(\mathrm{N}=6)$ or an isocaloric low protein diet $(\mathrm{N}=6)$ and then assessed for behavioral and physiological changes indicative of emotional changes. The low protein animals were found to eat more food but drink less of a sweet solution containing calories (sucrose) but not when the solution had no calories (saccharin). Low protein animals tended to secrete a less concentrated urine and had a shorter nose-to-anus length and smaller adrenals. No differences were found in body weight, body density, hematocrit, plasma total solids or open-field activity.
\end{abstract}

Nutritional deficiencies may well be a source of affective disturbances (Keys, Brozek, Henschel, Mickelson, \& Taylor, 1950; Zimmerman \& Stroebel, 1969). Most interest in protein deficiency studies has centered around the effects on development of the young. However, with the increasing cost of the most obvious sources of protein such as meats it becomes necessary to ask the question of the effects of protein deficiency on adults.

The essential amino acids must be ingested in the form of protein, as they cannot be manufactured by the body. Thus, deficiency of protein can be induced simply by feeding an isocaloric diet in which carbohydrate is substituted for some of the protein. In this experiment, two diets were used, one a normal protein test diet for rats $(26 \%$ casein) and the other a low protein test diet (3.5\% casein).

Simple quantitative food deprivation has been suggested to produce emotional disturbances. It is known to produce sexual response disturbances (Rosen \& Petty, 1974). Food deprivation generally is produced in such a way that nutritional deficiencies of all three major categories of food are produced. One possible result which might be the key to understanding the effects of general deprivation on sexual behavior is the reduction of available amino acids. Perhaps this is the key also to understanding the emotional effects.

The hypothesis of the experiment is that protein deprivation decreases affective responses. This hypothesis is supported by Zimmerman \& Stroebel (1969) who found that low-protein-fed monkeys showed apathy to their environments. Cowley and Griesel (1964) found that low-protein-fed monkeys were less

This research is based in part on a paper presented at the November 1971 meeting of the Psychonomic Society in St. Louis. The research was in part supported by a College Science Improvement Program from the National Science Foundation to the College of William and Mary to the first author. active in an open field and showed higher red blood cell count and smaller adrenals. To test this hypothesis, rats were fed isocaloric diets, one $26 \%$ casein and the other $3.5 \%$ casein. They were offered choices between a nonnutritive sweet substance (.5\% sodium saccharin) and water, between a nutritive sweet substance $(3.5 \%$ sucrose) and water, and between the two sweet substances. They were also tested in the open field and some physiological measures were made. The expectation was that the low-protein-fed animals would show a decreased preference for sweet substances and decreased activity in the open field.

\section{METHOD}

The subjects were 12 female albino Holtzman rats about 90 days of age. They were maintained on 24-h light at about $26^{\circ} \mathrm{C}$ in rat metabolism cages (Acme Metal Products). Animals were randomly assigned to one of two dietary conditions. Six animals were fed a normal protein rat diet (General Biochemicals No. 170590) and six an isocaloric low protein rat diet which substitutes corn starch for some of the casein (General Biochemicals No. 170580). The solutions used were .5\% soluble sodium saccharin and $3.5 \%$ sucrose. These solutions were made weight/volume using tap water.

The procedure was such that all animals had two bottles presented each day except Days 37-43 when only one bottle was presented. The bottles were alternated from side to side each day. On Days 1-4 all animals had the normal protein (NP) diet and two water bottles. On Days 5-16, the animals were fed the diet appropriate for their deprivation condition, either normal protein (NP) or low protein (LP), and had two water bottles. The differential feeding was continued throughout the rest of the experiment. On Days 17-20, the saccharin and water choice was presented. The saccharin first appeared (Day 17) on the preferred side. On Days 21-24, there was water in both bottles. On Days 25-28, the sucrose vs. water choice was offered with sucrose on the preferred side on the 1st day. On Days 29-32, both bottles had water. On Days 33-36, the choice of sucrose vs. saccharin was offered with saccharin first appearing on the preferred side. 


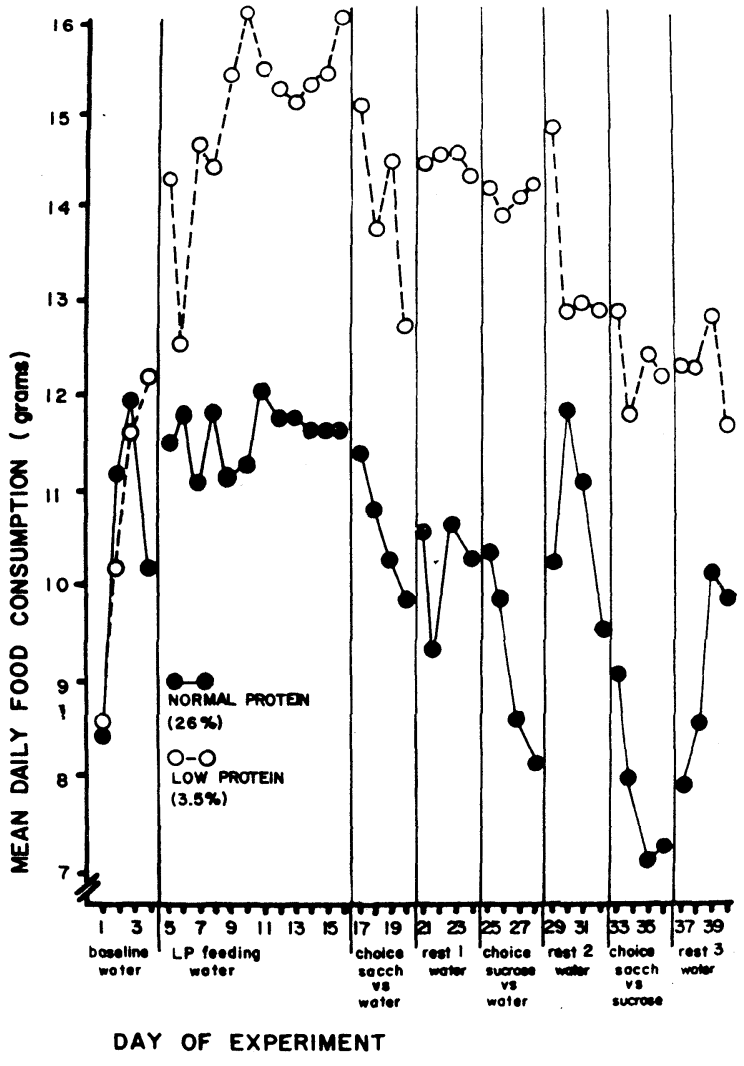

Figure 1. Average daily consumption by the normal and low-protein-fed animals.

On Day 41 , all animals were tested in a $45 \times 45$ in. open field for $5 \mathrm{~min}$. On Day 42, tail-blood samples were taken and hematocrit and plasma total solids (AO Goldberg Refractometer) were measured. On Day 43, the animals were sacrificed with an overdose of pentobarbital ( $1 / 2 \mathrm{cc}$ of 1 grain/cc). Nose-anus length and volume of water (cc) displaced when the animal was submerged were calculated. The adrenals were removed, and wet weight was determined.

On all days except Days 41 and 42, animals were weighed, and food and fluid consumption, urine volume output, and urine total solids were measured.

The significance level chosen for this experiment was $\alpha=.01$.

\section{RESULTS}

All data were analyzed as a diet by days analysis of variance for each period (Days 1-4, 5-16, 17-20, 21-24, $25-28,29-32,3341)$. The consumption and output results are summarized in Figures 14. During the first 4 days (NP diet only), there was no significant difference in body weight. Throughout the experiment, both groups showed a steady significant increase in body weight over days until Day $25(\mathrm{~F}=26.20, \mathrm{df}=11,110)$. Diet never had any effect on body weight $(F=6.48$, $5.38,2.08,1.69,2.60,0.88,2.60 ; \mathrm{df}=1,10)$. The final weights for the two groups are presented in Table 1.

Figure 1 presents the average food consumption. During the first 4 days when all animals had NP diet, there was no difference between the two groups $(F<1$, $\mathrm{df}=1,10)$. But for every period after that time, the $L P$ animals ate significantly more than the NP animals. Thus, though there were no initial differences in food intake when the LP diet is begun, the LP animals increase their intake and consistently eat more than NP animals (Fs for other periods $=39.27,39.47,42.79$, $20.22,17.37,40.51,25.65 ; \mathrm{df}=1,10)$.

Figure 2 presents the average fluid consumptions. On the saccharin vs. water choice, there seems to be little or no difference between the two groups (except perhaps for saccharin on Day 18) in either saccharin or water consumption. When water was the only solution offered (Days 21-24, 29-32, 37-40), there does not appear to be much difference between the groups. There also is no difference in water consumption during the sucrose vs. water choice. Both groups preferred the sucrose, but the NP group drank significantly more than the LP group $(F=58.3, \mathrm{df}=1,10)$. When offered the choice of sucrose or saccharin, the NP group preferred the sucrose and drank significantly more than the LP group $(\mathrm{F}=62.1, \mathrm{df}=1,10)$. There was no significant effects of diet on saccharin preference.

Figure 3 presents the total fluid consumption (total drunk from both bottles) and urine output throughout the entire experiment. There were no significant diet effects on either measure until the sucrose choice was

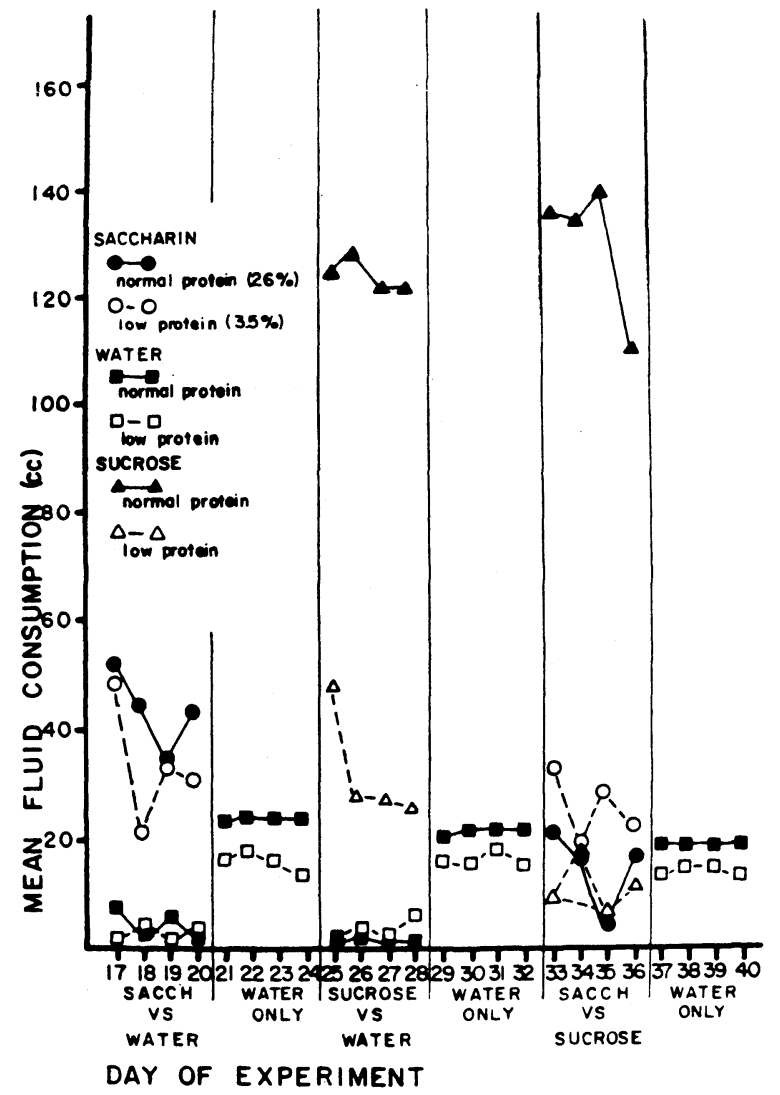

Figure 2. Average consumption of the sucrose and saccharin solutions and of water by the normal and low-protein-fed animals. 


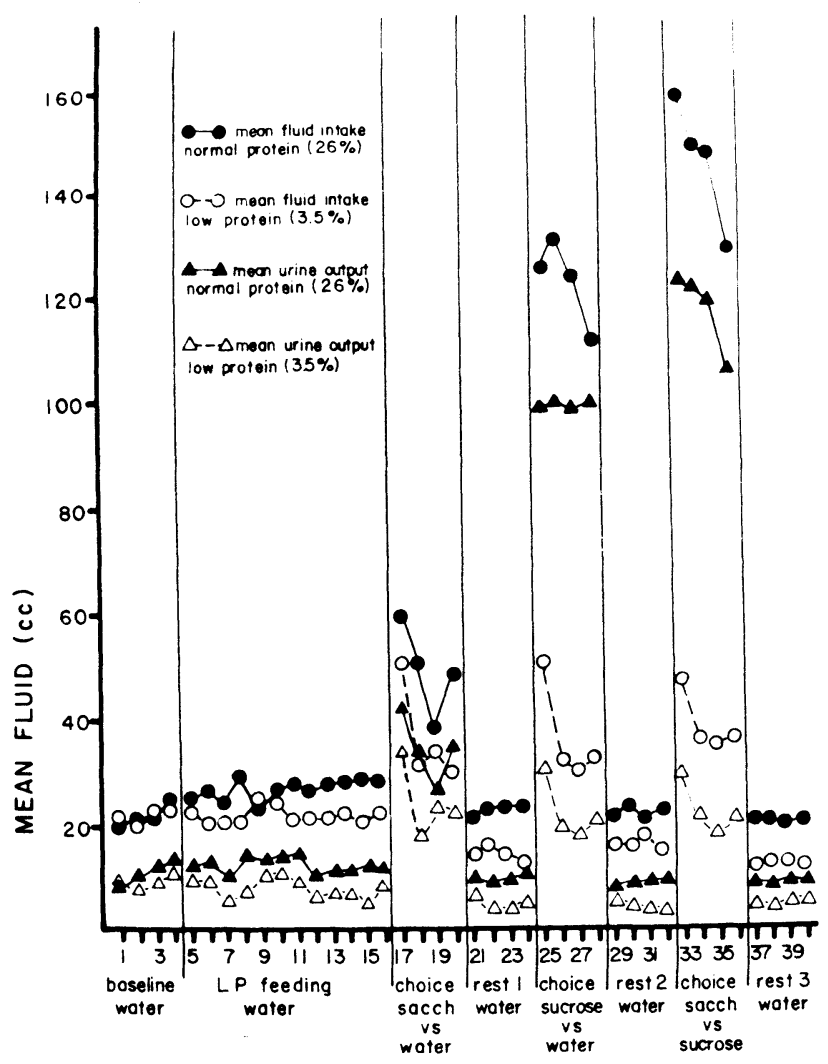

DAY OF EXPERIMENT

Figure 3. Average total fluid consumed from both bottles and average total fluid (urine) excreted per day by the normal and low-protein-fed animals.

offered. During the sucrose vs. water choice, the NP group drank significantly more fluids $(F=74.12$, $\mathrm{df}=1,10)$ and produced significantly more urine that the LP group $(\mathrm{F}=77.00, \mathrm{df}=1,10)$. This carried over through the following water rest period $(F s=12.25$, $14.09 ; \mathrm{df}=1,10)$ and continued when the sucrose vs. saccharin choice was given $(\mathrm{F}=60.03,76.78 ; \mathrm{df}=1,10)$. The significant differences disappeared in the third water period.

Figure 4 presents the urine total solids converted to urine concentration. This was done by using the conversion table for urine solids of the guinea pig (normal turbidity) (American Optical Company, 1964) and thus represents only an estimate. There were no significant diet effects except during the second and third water rest periods $(\mathrm{F}=11.87,27.77 ; \mathrm{df}=1,10)$.

In Table 1 are presented the remaining measures made during this experiment. The open field activity was scored as total number of grid crossings all over the field or number of crossings in the center (just of the innermost squares). Diet produced no significant difference in open field activity. There also were no significant differences in hematocrit or plasma total solids (an indirect measure of blood protein concentrations). The only significant difference found in any body size measure was nose-to-anus length $(\mathrm{t}=3.12$, $\mathrm{df}=10$ ). The LP group had significantly shorter bodies than the NP group. The LP group also had significantly smaller adrenals than the NP group $(t=3.96, d f=10)$.

\section{DISCUSSION}

In summary, LP feeding had no significant effects on body weight. When placed on a LP diet, animals increase their food consumption and consistently eat more than NP fed animals. Since the diets are isocaloric, this poses an interesting question: where did the extra calories go? They were not deposited as body fat since at the end of the experiment there was no significant difference in body weight or density. Also, they did noi show increased activity in the open field situation. However, this might be due to the novelty of the situation. The increase in food consumption under an LP diet is very reasonable: The animals must be trying to eat more protein by eating more food (Harper, 1967). In order to be able to do this, excess calories must be gotten rid of either by laying it down as fat (Harper, 1967 ) or by increasing activity levels (Collier, Squibb, \& Jackson, 1965a). In the present experiment, neither seemed to be the case. The open field measure of activity, however, could have been contaminated since Zimmerman and Stroebel (1969) have shown that, for monkeys, LP feeding yields a decrease in visual curiosity. Thus, though the LP animals might have been generally more active in their home cages, they may well be less active in a novel situation.

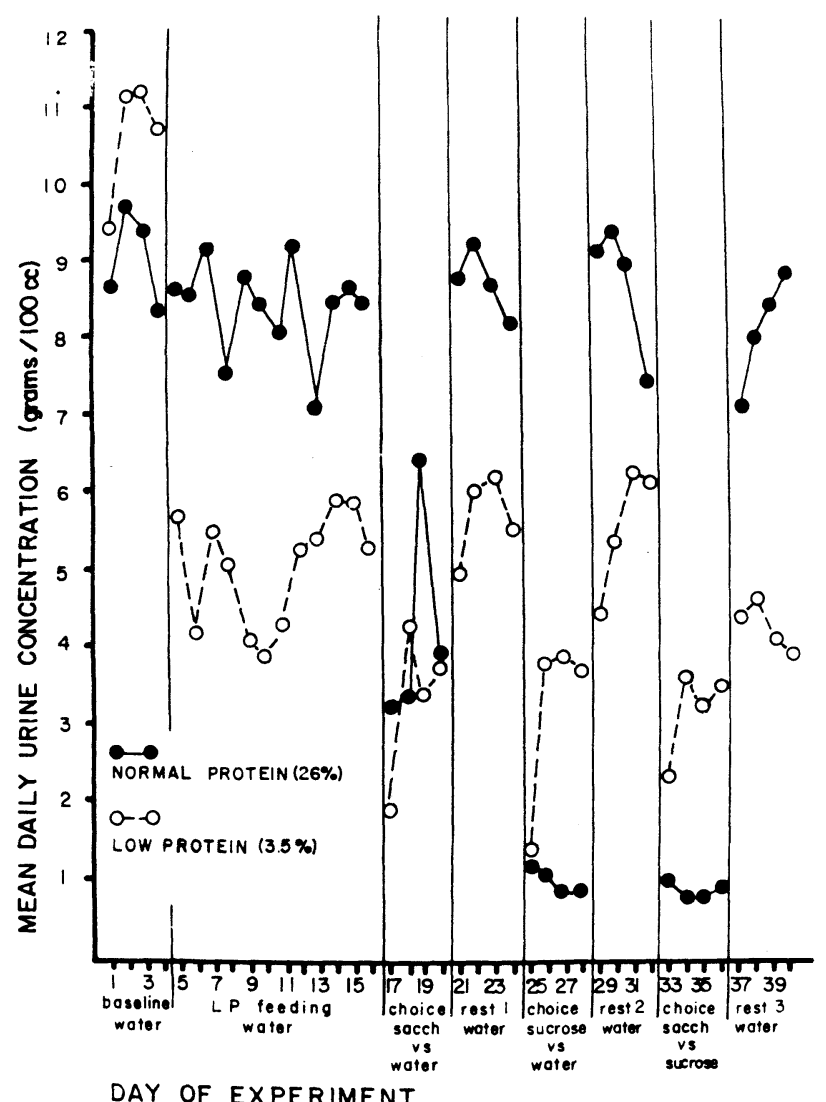

Figure 4. Average urine concentration of normal and low-protein-fed animals. 
Table 1

Summary Statistics of Measures Made of Other Behavioral and Physiological Responses to Low Protein Stress

\begin{tabular}{|c|c|c|c|c|}
\hline \multirow[b]{2}{*}{ Measure } & \multicolumn{2}{|c|}{ Low Protein $(\mathrm{N}=6)$} & \multicolumn{2}{|c|}{ Normal Protein $(\mathrm{N}=6)$} \\
\hline & Mean & SD & Mean & SD \\
\hline \multicolumn{5}{|l|}{ Open-Field Test (5 min) } \\
\hline 1. Total Grid Crossings & 123 & 44.2 & 126 & 31.4 \\
\hline 2. Center Grid Crossings & 6 & 3.7 & 13 & 6.6 \\
\hline \multicolumn{5}{|l|}{ Blood Determinations } \\
\hline 1. Hematocrit & 41.9 & 8.5 & 45.9 & 1.9 \\
\hline 2. Plasma Refractive Index & 159.2 & 15.5 & 165.3 & 6.4 \\
\hline \multicolumn{5}{|l|}{ Body Size } \\
\hline 1. Volume (cc Displacement) & 251.3 & 25.4 & 266.7 & 14.8 \\
\hline 2. Weight $(\mathrm{g})$ & 251.0 & 15.0 & 262.5 & 13.0 \\
\hline 3. Density $(\mathrm{cc} / \mathrm{g})$ & 1.0 & .08 & 1.0 & .03 \\
\hline 4. Nose to Anus Length (mm) & 213.2 & 4.0 & 220.0 & 3.6 \\
\hline \multicolumn{5}{|l|}{ Adrenals } \\
\hline 1. Adrenal Weight (mg) & 49.8 & 4.8 & 64.8 & 8.0 \\
\hline
\end{tabular}

In terms of fluid preference, only sucrose intake was dramatically altered by diet. Animals fed a LP diet respond to a noncalorie sweet-tasting substance like NP-fed animals, but, to a calorie carbohydrate, they showed decreased response. They probably are doing the reasonable thing: saving calories for food which has some protein. Their nutritional needs are better met by ingesting carbohydrate plus protein rather than just carbohydrate. This suggests that LP-fed animals do not have an altered preference for sweets per se but rather choose to spend their calories more wisely. Collier, Squibb, and Jackson (1965b) found that LP animals would not barpress as much for sucrose as NP animals. If they had used saccharin, this theory would predict that the difference would have disappeared. When they used a liver slurry. there was a tendency for the LP animals to press more than NP animals. Thus, behavioral studies of LP deficiency may be contaminated by motivational confoundings - a rat on an ad-lib regime will not find a sucrose solution rewarding whereas a saccharin solution may be.

Another interesting finding in the present experiment is that, for the NP group, the saccharin and sucrose solutions did not appear isohedonic. This is in spite of Young's assertion that "the optimal concentration for solutions of sodium saccharin is approximately $.50 \mathrm{Sac}$, and this optimal value is hedonically equivalent to 3.5 CHO" $(1967$, p. 357$)$. In the present experiment, they only appeared isohedonic for the LP-fed animals and not for the NP-fed animals.

Urine volume output seemed to closely follow total fluid consumption and seemed to be solely a reflection of consumption. The LP diet did, however, tend to cause the animal to excrete a less concentrated urine though the difference generally was not statistically significant. When sucrose was offered, however, the NP-fed animals drank so much fluid that their urine became less concentrated than the LP-fed animals, though not significantly. The other physiological measures made on these animals showed that the LP-fed animals were shorter in body length. Other researchers have found similar things (e.g., Beaton, Feleki, \& Stevenson, 1965). The LP-fed animals also had smaller adrenal glands.

In conclusion, the hypothesis of the present investigation was not supported. Adult female rats maintained on a LP diet do not show a change in preference for sweets if a nonnutritive substance is offered. However, if the substance has calories, they show considerably decreased preference relative to NP-fed rats. They also show no change in activity in the open field situation. However, they do have smaller adrenal glands than NP animals.
This would suggest that there ought to be some emotional effects of LP feeding. Perhaps differences would only appear under stressful conditions which do not enhance metabolism. Any stressful situation which enhances metabolism would be beneficial to the LP animals since they could then consume more food and thus become less protein deficient This has been shown to be true for both forced exercise and cold stress (Meyer \& Hargus, 1959).

\section{REFERENCES}

American Optical Company. Tables of properties of aqueous solutions related to index of refraction. Buffalo, New York, 1964.

Beaton, J. R., Feleki, V. \& Stevenson, J. A. F. Insulin hats fed a low-protein diet. Canadian Journa h Phy siology and Pharmacology, 1965, 43, 225-233.

Collier, G. H., Squibb, R. L., \& Jackson, F. Activity as a function of diet: I. Spontaneous activity. Psychonomic Science, 1965, 3, 173-174. (a)

Collier, G. H. Squibb, R. L., \& Jackson, F. Activity as a function of diet: II. Instrumental activity. Psychonomic function of diet: II. Instrum

Cowley, J. J., \& Griesel, R. D. Low protein diet ana emotionality in the albino rat. Journal of Genetic Psychology, $1964,104,89-98$.

Harper, A. E. Effects of dietary protein content and amino acid pattern on food intake and preference. In C. F. Code (Ed.) Handbook of physiology (Section 6). Alimentary canal (Vol. 1), Food and water intâke. Baltimore: Williams and Wilkins, 1967, 399-410.

Keys, A. Brozek, J., Henschel, A., Mickelsen, D., \& Taylor, H. D. The biology of human starvation. Minneapolis, Minn: University of Minnesota Press, 1950.

Meyer, J. H., \& Hargus, W. A. Factors influencing food intake of rats fed low-protein rations. American Journal of Physiology. $1959,197,1350-1352$.

Rosen, E. F., \& Petty, L. C. Food deprivation effects on some estrogen-sensitive responses in female rats. Physiology and Behavior, 1974, 12, 475-479.

Young, P. T. Palatability: The isohedonic response to foodstutts. In C. F. Code (Ed.), Handbook of physiology (Section 6) Alimentary canal (Vol. 1). Food and water intake. Baltimore: Williams and Wilkins, 1967, 353-366.

Zimmerman, R. R., \& Stroebel, D. A. Effects of protein malnutrition on visual curiosity, manipulation, and social behavior in the infant rhesus monkey. Proceedings of the 77th Convention, American Psychological Association, 1969, 4, 241-242.

(Received for publication March 17, 1975.) 